\title{
Design-led approaches to crafting conversations in the circular economy
}

\begin{abstract}
This paper explores the work in the area of Material Futures - undertaken by researchers at The Glasgow School of Art (GSA). We begin by presenting current debates within the textile sector and outline the challenges of the circular economy. The Scottish Government have established a $£ 17$ million fund to catalyse innovative approaches for the circular economy, which support closed-loop systems including collaboration, evaluation of different methods and future material ecologies. We discuss future material ecologies in two case studies in order to extrapolate the ways in which creative and participatory design approaches can be used to stimulate dialogue around the circular economy, broader environmental and economic issues and the socio-cultural implications. We identify six design principles for researchers and practitioners to consider when facilitating circular conversations and the evolving role of the textile designer. We go on to highlight the significance of design-led approaches in strengthening communication, promoting creative action and embedding collaborative ways of working. We conclude by making recommendations for future research and practice and how the insights might be expanded upon to support ethical, responsible and sustainable material futures.
\end{abstract}

KEY WORDS: design; conversations; material futures; textiles; circular economy.

\section{INTRODUCTION}

Heightened awareness of the economic value being lost through waste coupled with a rise in resourcing risks have elevated business interest in the circular economy. While the term circular economy is becoming appropriated on a global scale to address a wide range of issues regarding waste, there is little evidence available to demonstrate how this might be applied by small to medium enterprises (SMEs) and understood by Higher Education (HE). A recent study by McKinsey (2015) identified that resource productivity remains hugely under exploited as a source of wealth, competitiveness and renewal. McKinsey argue that a circular economy, enabled by the technology revolution, would allow Europe to grow resource productivity by up to three percent annually. Within the UK, the Scottish Government has implemented a $£ 70$ million European Regional Development fund including a £17 million Circular Economy Investment fund to help SMEs to catalyze innovative approaches to design - fostering repair and reuse and encouraging service and leasing models for material recovery - with the premise of supporting closed-loop systems. Highlighting additional support for collaboration, the evaluation of different methods and textile technologies and sustainable future material ecologies. We propose that design-led approaches can play a key role in addressing these innovation challenges:

The skills that must be developed in the new circular economy [...] are new behaviors, new ways of collaborating and new ways of seeing. And for these to be learned and ingrained, they must first be tested and actively encouraged (RSA, 2016: 41).

This paper explores the work on Material Futures undertaken at The Glasgow School of Art during 2016 and 2017. In doing so the researchers seek to raise awareness of the circular economy in the Scottish textile sector by identifying the most appropriate design-led approaches for crafting circular conversations towards addressing gaps in both knowledge and practice. The research investigates how to connect textile designers with wider stakeholders through asking what design principles are required to craft conversations around the circular economy in relation to developing new material concepts. 
We outline current debates within the textile industry and frame the innovation challenges in the circular economy. We then present two case studies from the field of design research in order to extrapolate the ways in which creative and participatory design approaches can be used to stimulate productive dialogue around the circular economy and broader textiles issues. From there we identify six design principles for textile researchers and practitioners to consider when facilitating such conversations. We conclude by reflecting on the implications of these principles for future research and the role of the textile designer and highlight the significance of designled approaches in stimulating innovation, promoting creative action and embedding collaborative ways of working.

\section{TEXTILES: CURRENT DEBATES}

Sustainability in textile manufacturing has been the focus of much textile research (Fletcher et al, 2014), which is, in the main, concerned with textile manufacturing, materials and processes and their environmental impact, rather than from the perspective of the circular economy and its socio-cultural significance. We propose a broader research perspective that encompasses the social and human dimension. Expanding the sustainability argument beyond manufacturing and its ecological implications reframes the current debates around developing new socially cohesive textile initiatives, innovations and industries. This emphasizes the value of socially sustainable practices for a competitive textiles and fashion industry. Since the early $21^{\text {st }}$ century social challenges and sustainable communities have emerged as a key policy concern. Stable and selfsustaining communities are predicated on competitiveness, collaboration and the knowledge economy, and in so doing contribute to the political agendas of growth and the development of jobs and communities (Padovani \& Whittaker, 2016).

This extends to embedding new contextually located socio-cultural behaviors that include encouraging new ways of being, seeing, acting and meaning making. This is aligned to the importance of place in current debates around material thinking and developing an approach that focuses on place as a mode of designing for sustainability and future material ecologies (Kane, 2017).

In terms of design, these ideas support the notion that the evocation of place through design is powerful, connecting us with and contributing to the making of such meaningful locations [...]. With regard to sustainability, ideas about place have often focused on close connections between a region and its ecosystem (Kane, 2017: 102).

The innovation challenges of socially sustainable textiles and the attendant ecosystem revolve around creative approaches that underpin closed-loop innovation and the adoption of new sustainable practices. There is growing interest from policy makers who view the creative industries as a stimulus to develop local and regional economies, skills and resources in relation to wider circular economy networks and business models (Yair, 2011). Material design for sustainability can be positioned as a conduit in the revitalization of regional economies and as a mechanism to support collaboration, closed-loop innovation and new initiatives in the creative economy.

\section{DESIGNING FOR CIRCULARITY}

Within the UK textile sector there is increasing awareness of the requirement for new textile initiatives linked with the concept of the circular economy (Goldsworthy, 2012; 2013). However, there is a lack of practical knowledge and accessible evidence available to provide support to SMEs and wider stakeholders in the textile sector. According to Scottish Enterprise, the textile sector has highlighted that there is a lack of resources for research and development (R\&D) and business model innovation (Scottish Enterprise, 2013). Scottish based textile and fashion SMEs are currently adding value to previously discarded textile waste by applying their practical skills, knowledge and expertise to rework and reuse textile surplus and waste (Simonella, 2016; Kent, 2016; Taylor, 2015). From a broader perspective fashion and textile designers have been adopting sustainable design principals and strategies, with a range of examples emerging in the 
last decade. These demonstrate new concepts such as: zero waste pattern cutting (Gwilt and Rissanen, 2011; Rissanen and McQuillain, 2015); design for disassembly (Van Balgooi, 2015) and; upcycling (Earley, 2015; DeCastro, 2015). Designers working with post consumer textile waste highlight that the scope of redesign is often influenced by the first lifecycle of the garment or textile. The circular economy model presents a new position by arguing for a case for circular economy and new material concepts to embed closed-loop innovation from the outset. The circular model proposes an holistic approach, with design for sustainability discussed at the front end of the innovation process (Ballie, Smith \& McHattie, 2016). Design approaches that consider multiple cyclical iterations or loops of use at the outset could fully optimise lifecycles and reduce post-consumer waste. These approaches expand on the research undertaken by Payne (2011), as shown in Figure 1.

\section{Conversation, Collaboration, Innovation - Promoting Lifecycle thinking in fashion design process}

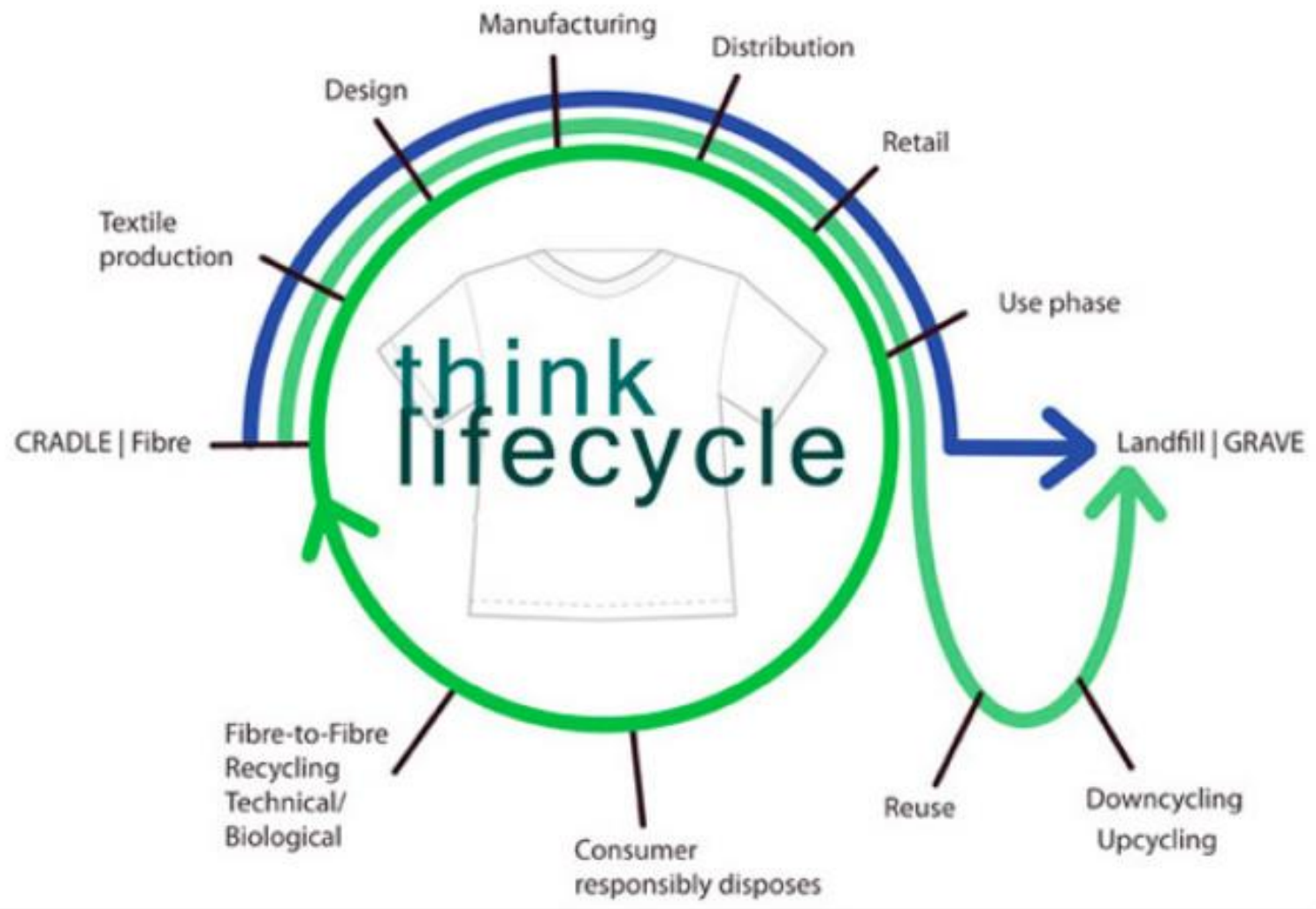

Figure 1: Mapping out the lifecycles of a fashion garment. Promoting lifecycle thinking in fashion, Alice Payne (2011).

Whilst design capabilities have been sustained within the UK, manufacturing skills have not (Taylor and Townsend, 2014). This presents a dilemma for UK businesses that must not only begin to address the issue of skill shortages but also develop new business models that take account of provenance, longevity, environmental impacts and end-of-life (Thomas, 2015).

We have outlined in this section insights around place, process and ethical awareness in the context of textile design. We now go on to present two case studies in which design-led approaches are applied to enhance participants' awareness of and capacity to respond creatively to the concept of the circular economy.

\section{COMMUNICATING CIRCULATRITY: DESIGN-LED APPROACHES IN ACTION}

The case studies presented provide accounts of two research projects in which design approaches have been developed to engage diverse groups of people in conversations around 
environmental and socio-cultural issues in the context of the circular economy. Case study one refers to Re-Mantle and Make as an approach to re-thinking through making. Case study two offers an overview of Circular by Design workshops, in which creative and generative materials were developed to unpack perceptions of and envisage strategies to enhance the circular economy with a group of textile designers. These accounts set the scene from which we then go on to focus on how creative and participatory approaches were constructed in each case to render often abstract concepts tangible and accessible and identify guiding design principles towards crafting conversations around the circular economy.

\section{Case Study One: Re-thinking through Making - Re-Mantle and Make}

The six-month feasibility study led by The Glasgow School of Art, was part of a project entitled Future Makespaces in Redistributed Manufacturing, a two-year research project funded by the Engineering and Physical Sciences Research Council (EPSRC).

The study investigated how maker spaces could be used to cultivate circular thinking for textile designers and to provide them with resources to develop circular design knowledge and practice. The term Re-Mantle and Make was a provocation to challenge makers' perceptions of textile and fashion artefacts. This project demonstrated how a new model for future maker spaces could be developed to experiment with sustainable design strategies for material recovery, repair and reuse on a local scale by providing creative hubs for designers to come together to collaborate, experiment and learn.

There are currently limited practical examples of products and services in the circular economy including a lack of evidence of closed-loop innovation within the textile sector and the potential impact these approaches can contribute to knowledge and practice. This case study explores the barriers and opportunities in the circular economy towards embedding closed-loop approaches. The series of make-a-thon workshops were held in maker spaces in two geographic locations, Glasgow and Forres during 2017 and undertaken in partnership with Kalopsia Collective, a micro-manufacturing unit based in Edinburgh. The aim of the project was to conduct practice-led research in the circular economy and to produce a small collection of fashion accessories from surplus textile waste sourced from local Scottish based textile manufacturers, including lace, cashmere and leather surplus streams.

The exploratory model was designed to prototype a new approach for a circular fashion system on a local scale specifically within Scotland's textile sector. It is important to acknowledge that this was a feasibility study designed to initiate partnerships and produce prototypes, which endeavored to preserve and enhance socio-cultural capital, optimizing the use of resources and foster new material concepts through both utilizing and designing out waste. Three designers were commissioned to produce circular textile artefacts with an accompanying zero waste pattern in response to a design brief. The brief built upon the work of Earley and Fletcher (2003) who highlight "Fashion clothes capture a moment in time and are as quickly forgotten [...] what if that moment was not one but many moments... a process of transformation?" (Earley \& Fletcher, 2003).

The artefacts were presented in a final Re-Mantle and Make showcase along with the textile techniques and patterns and contributed to a round table conversation with participants and wider stakeholders. The round table brought together textile manufacturers, higher-education institutions, researchers and practitioners, SMEs and policy makers 'in conversation' to develop recommendations for future collaborations. In addition to considering how alternative supply chains could be conceptualized to investigate the potential for sustainable, material futures in the textile industry. To underpin the round table forum a life cycle analysis tool was designed to facilitate the discussions and tease out the innovation challenges and opportunities for embedding circular thinking into the initial design phase and the potential impact on the wider system. This extended to reflecting on the artefacts and prototype designs in terms of how they responded to the circular economy principles and broader socio-cultural implications towards exploring and embedding future ideas for circular innovation. 


\section{Case Study Two: Re-thinking Supply and Demand - Circular by Design}

This case study draws on a workshop activity Design Better Things: Do better things hosted by Zero Waste Scotland (Feb 2016). The brief was to stimulate conversation around circular innovation with participants from across the UK textile sector. A Circular by Design (Ballie and Woods, 2015) canvas was designed, which presented a linear supply chain and encouraged participants to 'hack' into a circular loop to connect the flow of materials, towards identifying opportunities around material efficiency and reuse. The Circular by Design canvas was developed to mediate opportunities for joined-up thinking and practice by supporting designers, SMEs and micro businesses to identify opportunities for closed-loop innovation (Figure 2). The canvas aimed to encourage designers to consider future scenarios for products and services both during the development process and for after use. The approach encourages consideration into end-of-life strategies at the beginning of the design process through to considering both shared and discreet assets across the supply chain. These assets extend to physical assets such as: fibers, processes, materials, techniques and technologies and cultural assets including: people, place and practice (McHattie et al, 2018).

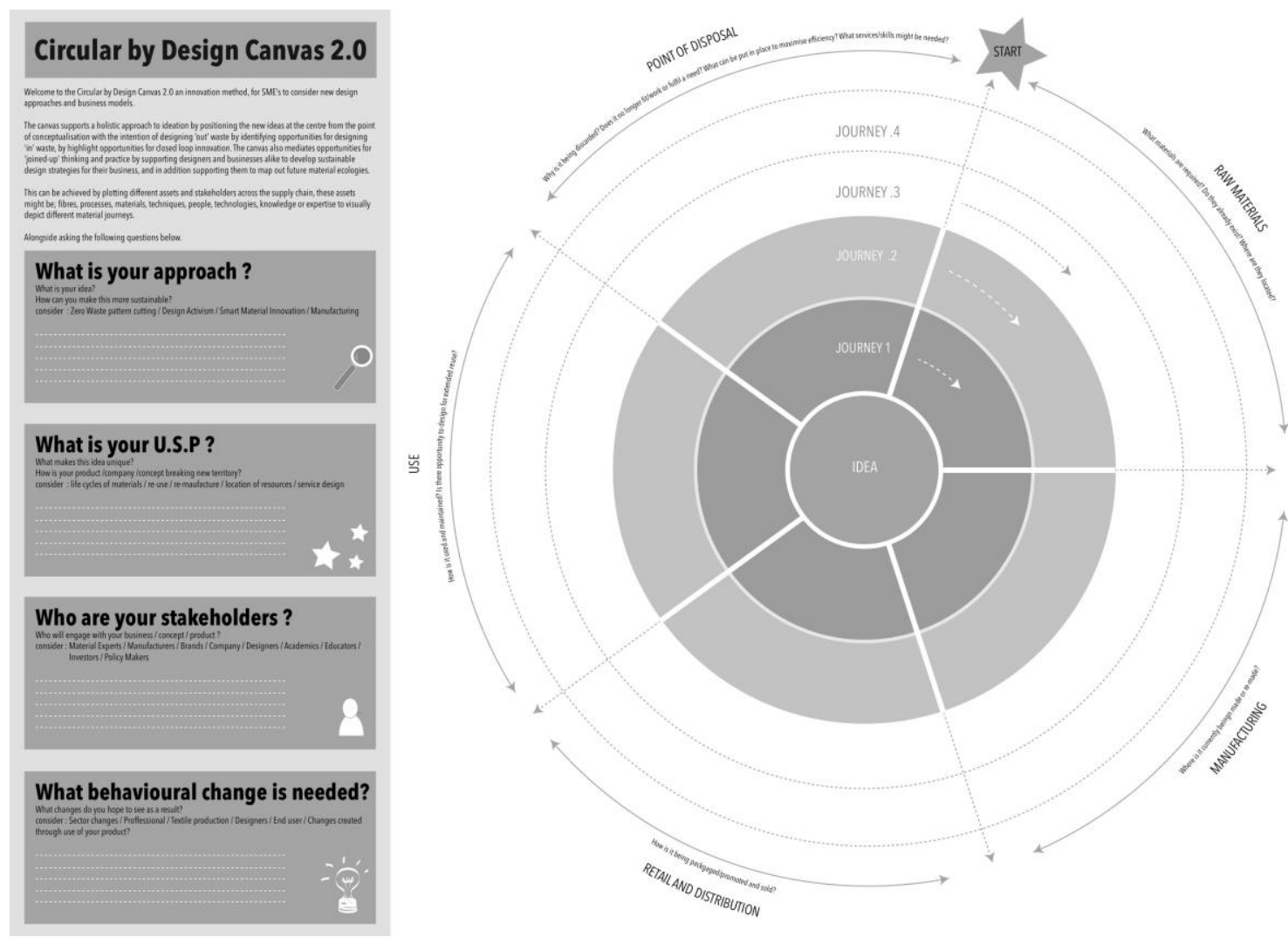

Figure 2: Circular by Design Canvas 


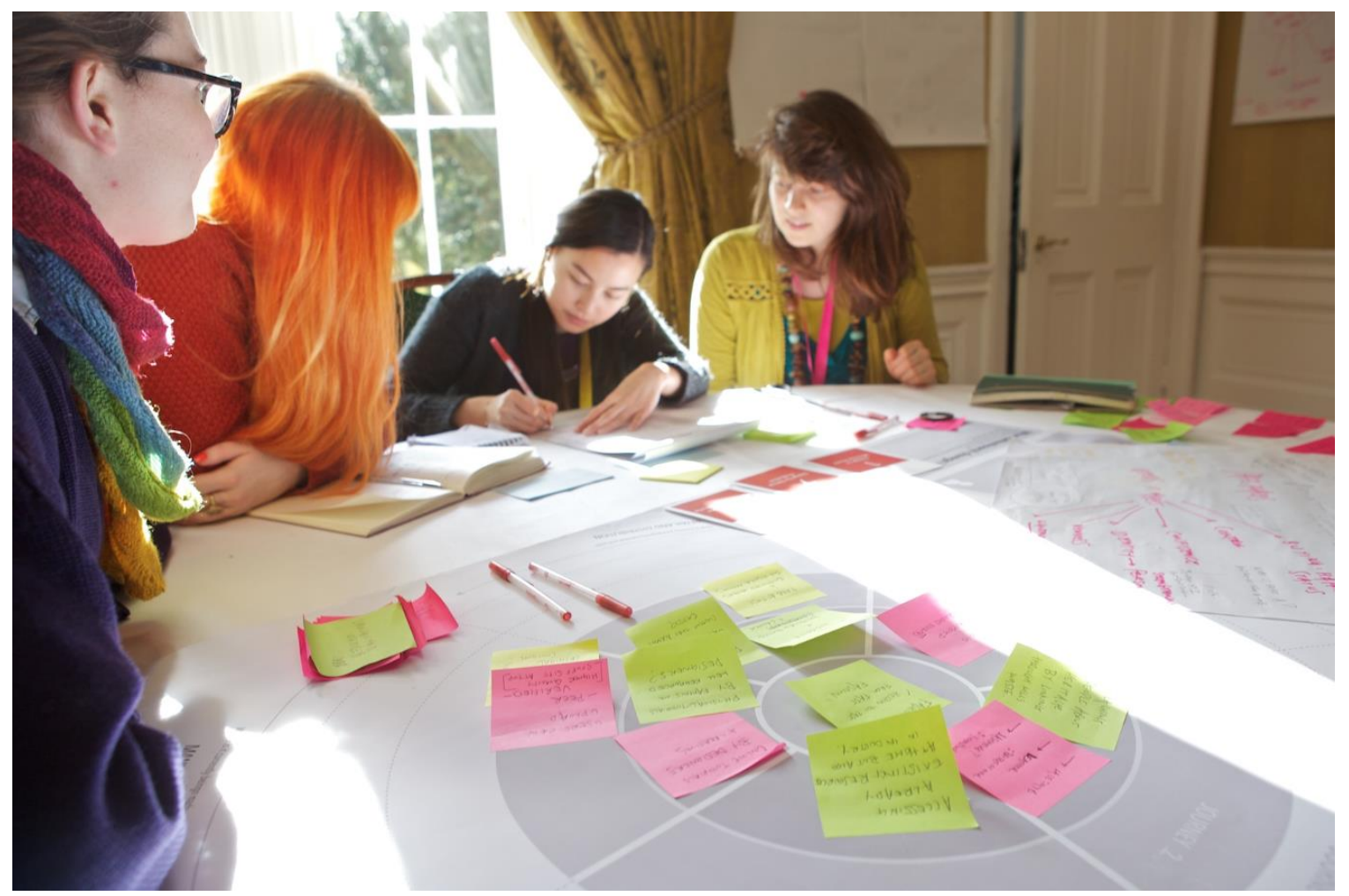

Figure 3: Circular by Design Canvas in Use

The task mediated re-thinking supply and demand as an approach to Circular by Design and encouraged individuals to work within groups to visually depict new material journeys. This effectively provoked debate around new possibilities, alongside identifying barriers and opportunities for future development. Whilst we can invest our collective energy, efforts and expertise into designing responsible products and services it could be argued that without socio-cultural behavior change and policy intervention it is difficult to ascertain if this can this have a meaningful impact in a world populated with too much stuff.

The Circular by Design conversations highlighted a wealth of creative solutions with the overarching ambition to develop a series of design guidelines towards ascertaining if existing or future products had the potential to be remade. This would extend to the analysis of quality and durability, the ability to seamlessly reconstruct textile waste and the streamlining of the remaking process to ensure efficiency and cost effectiveness. The Circular by Design canvas and participant conversations provided valuable insights into the feasibility of design-led approaches in the circular economy. Multiple forms of value are key in underpinning circular approaches beyond economic value. Delivering economic value was not viewed as a primary driver by participants and other forms of socio-cultural value emerged, such as the social and environmental value applicable to a broader range of stakeholders. When discussing their strategies and approaches designers focused on changing consumer habits towards longer life textiles and apparel and demonstrated an interest in producing garments that are easy to care for, repair, upgrade and recycle.

There have been recent discussions in the design field around the circular economy towards developing dematerialized consumption patterns through shifting the focus in design from material possessions to accessibility and services (Shayler, 2016). The conversations in the Circular by Design workshop highlighted the potential for exploring innovative ways that textile and fashion designers may begin to alter conspicuous consumption behaviors by offering viable alternatives. It was evident that products should be viewed as something that will forever need completion and the designer's evolving role as a facilitator of this process as opposed to the design and finalization of a product. Additionally, if we want to see changes in the consumption patterns of fashion or indeed consumer attitudes it is incumbent for designers to create circular systems, which embed the knowledge and practice of lifecycle design, as a 
priority. In summary, Circular by Design conversations were punctuated by imperatives such as, innovation, greater resilience against future risks, eliminating needless impacts and new business models. In this manner, circular conversations can create new spaces for ideas and action that are contextually located.

\section{INSIGHTS AND REFLECTIONS: SIX DESIGN PRINCIPLES FOR CRAFTING CONVERSATIONS AROUND THE CIRCULAR ECONOMY}

In the following section, we draw together insights and reflections from two case studies' ReMantle and Make and Circular by Design. The case studies frame the specific context for conducting conversations. Designing 'in conversation' and understanding a context are closely related to one another. Following a conversational approach designers can respond iteratively to the six principles through direct communication with people, participants and their communities. It is the synthesis of these conversations that underpin the design principles for crafting conversations around the circular economy. We now go onto discuss how the case studies contribute to the six speculative design principles that have the potential to support design researchers and practitioners in crafting productive conversations around the circular economy.

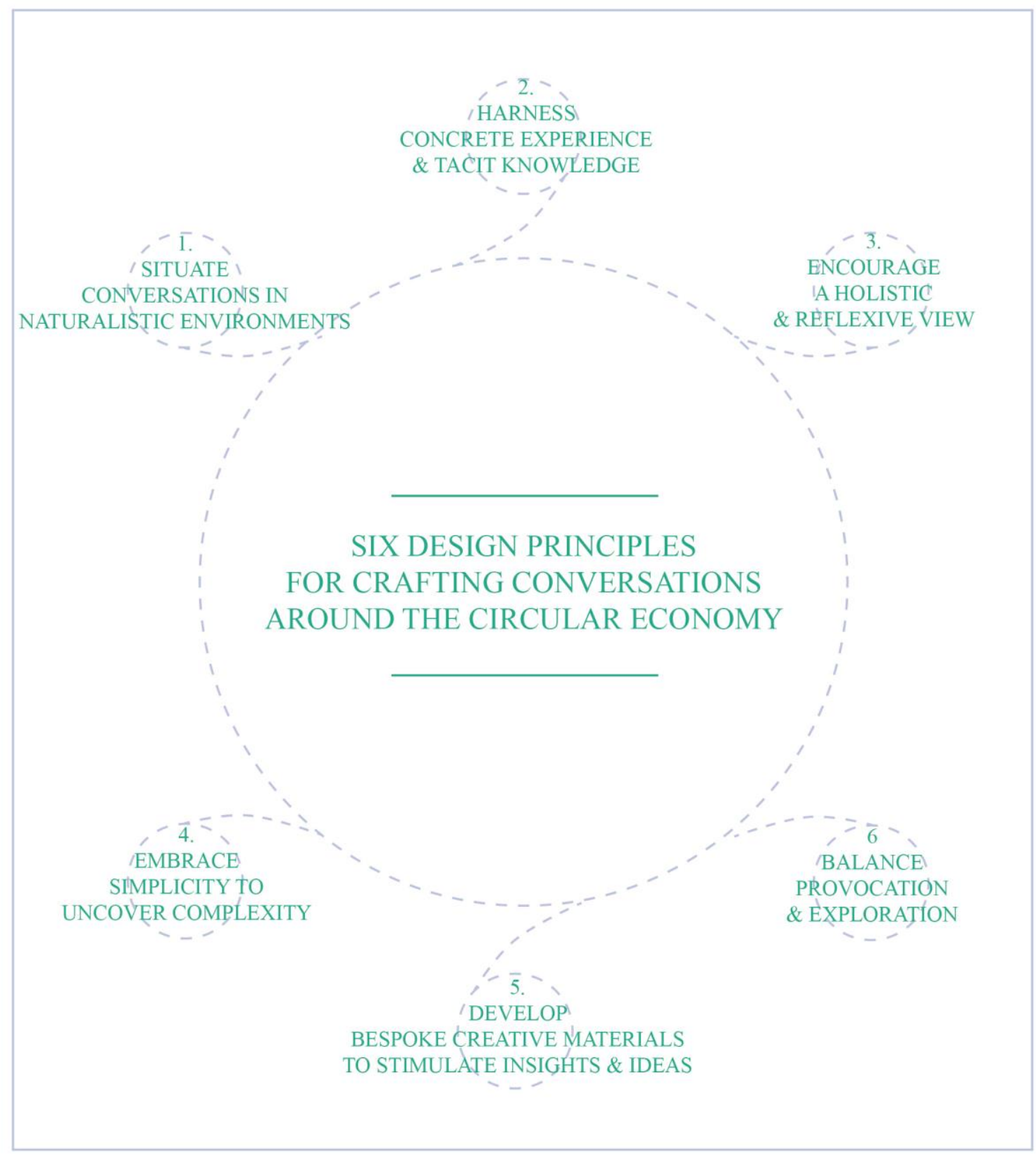

Figure 4: Six Design Principles for Crafting Conversations around the Circular Economy 


\section{Principle 1. Situate Conversations in Naturalistic Environments}

We propose that the experiential qualities of the natural environment and a deep understanding of context and place offer an immersive setting for participatory activities and can situate conversations within the specific context that they seek to address.

Conversation 1: The series of Re-Mantle and Make workshops were held in maker spaces in two geographic locations, Glasgow, in the Strathclyde region and Forres, in the Highlands and Islands of Scotland. The workshops introduced participants to circular thinking and new material concepts in the environment of a maker space. These regional and immersive settings provided participants with a contextually relevant space to engage with the textile waste and surplus in situation. Designers are often disconnected from the process of manufacturing and the surplus resources engendered multiple opportunities to re-think making from sourcing raw fibers and materials to the production or reassembly of a finished artefact.

Conversation 2: Circular by Design took place in workshop settings in Glasgow and Edinburgh, the workshops foregrounded a circular approach to designing in the textile sector. There is a range of natural environments that can be used to situate contextually located conversations around, for example, the richness of Scottish raw materials including natural and noble fibers; such as fleece from crofts and the spinning of yarn for weaving and knitwear. These conversations draw on what we term the 'deep process wisdom' found in the supply chain and are elaborated on in the following principle (McHattie et al, 2018).

\section{Principle 2. Harness Concrete Experience and Tacit Knowledge}

In supporting participants to share their experiences and collectively consider ways to address complex societal challenges, design researchers must develop approaches to harness concrete experience and tacit knowledge.

Conversation 1: Re-Mantle and Make revealed conversations around deep process wisdom predicated on experience and tacit knowledge. Examples include material recovery, repair and reuse on a local scale by providing a creative environment for designers to share their collective wisdom. Through the Re-Mantle and Make make-a-thon sessions participants worked together to prototype artefacts from waste and surplus streams, which can be re-made in the future. The high quality surplus materials provided a rich medium for the designers to consider multiple design iterations through combining their specialist skills and collective wisdom.

Conversation 2: The Circular by Design conversations were enhanced through the skills, techniques and material literacy embodied within the textile designers in the group. Their knowledge mediated the exchange of insights and approaches towards identifying potential new material concepts. These concepts connect the flow of materials towards identifying opportunities around material efficiency and reuse based on embodied knowledge and practice.

\section{Principle 3. Encourage a Holistic and Reflexive View}

By bringing together a diverse range of people and developing bespoke methods and approaches to spark dialogue, circular conversations should focus on both the intricacies of the challenge at hand and their implications on a systemic, global scale.

Conversation 1: The Re-Mantle and Make artefacts and commissioned designs were presented in the final showcase along with the textile techniques and patterns and contributed to a round table conversation with participants and wider stakeholders. The circular artefacts provided a stimulus to prompt reflective conversations and provide material touch-points around which participants considered closed-loop innovation challenges in design, production and consumption. The broad range of stakeholders and participants considered how their collective capabilities could influence both designers and end users towards how we re-define waste materials and change socio-cultural behaviors at a systemic level.

Conversation 2: The Circular by Design tool was developed to mediate opportunities and encourage an holistic approach. The participants physically constructed a closed-loop process, 
during which they discussed the wider implications of the circular economy, this provided them with a view of the wider fashion system. We propose that such a holistic perspective can enhance how participants position themselves within the system and reflect on their design process as both part of the problem and equally part of the solution. This underpins the evolving role of designers to reflexively negotiate their role within material ecologies and their capacity to take action.

\section{Principle 4. Balance Provocation and Exploration}

Design approaches are flexible and malleable, and can be tailored to correspond to open and exploratory activities, as well as to accompany targeted forms of questioning.

Conversation 1: The term Re-Mantle and Make was defined as a provocation to challenge makers' perceptions of textile and fashion artefacts. Indicative of how provocative approaches can prompt emotional responses, exploratory conversations focused on emergent design and co-design possibilities beyond conventional responses. Design approaches require to be well considered to ensure there is a relevant context of use for the consumer, who in addition needs to be empowered to 'hack', experiment with or modify the end product as a form of creative exploration.

Conversation 2: The Circular by Design task mediated re-thinking the supply chain and encouraged participants to work in groups to visually depict new material journeys. This effectively provoked debate around new possibilities, alongside identifying barriers and opportunities for future exploration and closed-loop innovation. The Circular by Design conversations revolved around a linear supply chain and how this could be 'hacked' to encourage closed-loop innovation. These conversations alluded to a paradox in power dynamics whereby the designer does not have as much influence as one would imagine. In some instances, 1,000 pairs of hands touch a piece of clothing before it reaches a consumer (Lee, 2008).

\section{Principle 5. Develop Bespoke Creative Materials to Stimulate Insights and Ideas}

Evoking the hands-on, generative nature of participatory design approaches as a means of enacting the future (Brandt et al, 2013).

Conversation 1: Three designers were commissioned by Re-Mantle and Make to produce bespoke artefacts with an accompanying zero waste pattern in response to a design brief. The brief built upon the work of Earley and Fletcher (2003) who highlight "Fashion clothes capture a moment in time and are as quickly forgotten..." to stimulate insights and ideas. In the make-athon sessions, the participants selected surplus materials and sampled different techniques including 3D printing, embroidery, laser cutting, knitting and table top weaving or a combination of these. However, it was only through sharing ideas 'in conversation' that the potential of the bespoke artefacts became generative in nature.

Conversation 2: The bespoke Circular by Design tool was developed as a creative conduit for circular conversations and provided participants with stimuli to talk through closed-loop innovation. Through applying the 'hacking' metaphor participants subverted the linear supply chain and used lo-fi craft materials that could easily be re-configured and re-assembled. In this sense, design researchers have a role to play in developing bespoke materials, methods, tools and approaches in response to both the local objectives underpinning specific projects and the aims governing wider research agendas.

\section{Principle 6. Embrace Simplicity to Uncover Complexity}

The methods and approaches developed to examine complex issues in both case studies appropriate Eriksen's (2009) participatory design tools as basic materials and pre-designed images and artefacts. Lucero et al. observe that a diverse array of materials with varying levels of simplicity, specificity, and provocation gave way to "a relaxed atmosphere since participants are not forced into activities they are not comfortable with", and stimulated "a structured but flexible way in order to spark dialogue between the co-design participants and thus support idea generation" (2012: 19-20). 
Conversations 1 and 2: In both case studies Re-Mantle and Make and Circular by Design

participants were encouraged to engage in deep reflection on both their individual and

collective roles in addressing the grand challenges in the circular economy and sharing their deep process wisdom. Akin to ecology, systems design requires a complex understanding of the wider ecosystem and awareness of the embedded components as shard resources. In this manner, conversational tools have the potential to unearth some of deeper issues, foster new insights and develop innovative responses.

\title{
CLOSING THE LOOP: IMPLICATIONS FOR THE TEXTILE SECTOR
}

The Six Design Principles emphasize the need for creative and participatory methods and approaches to enhance cross-disciplinary, cross-sector awareness and the requisite understanding of designing for a circular economy.

With $80 \%$ of a product's impact determined at the design phase, there is a compelling case to explore the role that designers can play (RSA Great Recovery, 2014). Design for sustainability theorists believe it is more efficient to work with preventative solutions rather than adopt systems that deal with damage control (Manzini and Vezzoli, 2008). Designers are using co-design approaches (Sanders and Stappers 2008 rather than individual authorship to understand and meet complex needs. In this manner new tools and platforms are becoming more effective than finished artefacts (Thackara, 2013). This is part of a shift towards trans-materialization, where innovation design concepts are evolving in parallel with product design development to construct new scenarios of use, reuse, design and redesign. To work this way, designers need to acquire new skills, knowledge and experience to enable them to act as social innovators and become agents of change. Instead of designing from the constrained perspective of a client's brief, designers now accommodate the complexities of designing for society and embrace new collaborative ways of working:

\begin{abstract}
A design outcome may not always be a physical, tangible product. It may be a service or a new way of doing things. In some cases, we may not need a new product, just a better way of integrating the products we already have in order to serve our needs. Design is also too important, and too useful, to be used only by professional designers. The active participation of users in the design process can ensure more successful design outcomes. The emergence of open-source design is creating a collaborative remix culture in which the originator of an idea passes it on to others to take in new directions (Chick and Micklethwaite, 2011: 35).
\end{abstract}

In spite of such shifts within the broader discipline of design there is limited literature relating to the role of the specifics of ethics within the fashion or textile industry including acknowledging responsibility within the supply chain and the lifecycle of a garment. Traditionally fashion designers do not write or theorize - they cut and make (Thomas 2001: 4). Desires to rationalize design can be seen to overshadow the practitioner's skill and agency and as Dorst asserts, the discipline's preoccupation with understanding processes and methods disregards the individual designer's ability to negotiate complexity in diverse settings (2008: 5, 8). Whilst interrogating the modus operandi of the fashion industry, there could also be an interrogation of sustainability and the circular economy and the social, cultural and environmental impact if universally adopted by design practitioners and the fashion and textile industry in general.

\section{CONCLUSIONS}

The reviewed literature has highlighted that currently there are limited practical examples of circular innovation within the textile sector and designers will require support moving forward. There is a dearth of evidence of circular fashion systems at all scales, from the local and unique to the global and mass-produced. Fashion and textile designers will need to collaborate across disciplines to innovate new material concepts. Moving forward knowledge exchange will be essential alongside introducing innovative tools to mediate designerly dialogue and support 
joined-up thinking to connect all stakeholders involved in the supply chain. Practically, designers have the potential to unlock hidden potential within supply chains and materials.

The research presented within this paper highlights the importance of acknowledging that the circular economy goes beyond the capabilities of specific design disciplines and positions action as a shared responsibility that cannot be undertaken in isolation. This will require participatory approaches, which include the input of craft practitioners, material scientists, business experts, waste managers and policy makers alongside other stakeholders and those undertaking roles that have not yet been identified. It is through grappling collaboratively with these challenges 'in conversation' that dialogue may be shifted beyond rhetoric into responsible and sustainable action.

The six design principals outlined in this paper emerged in response to the literature and the two case studies towards a transitioning beyond traditional paradigms. Whilst emergent, they provide a framework to facilitate crafting circular conversations to continue the discourse on how we might expand upon the role, skills and capabilities of designers to equip them to operate within a circular economy. Future approaches will seek to apply, evaluate, and iterate the principles through further participatory activities, and explore their flexibility and transferability when developed by other design researchers situated in similar contexts of inquiry.

Further research is required, which will focus on collective conversations as a way of embedding social innovation and cohesiveness within the social fabric of new material futures, underpinned by creative approaches that harness the qualities of making and design sensibilities towards the adoption of new sustainable and responsible practices in the circular economy. 


\section{REFERENCES}

Andrews, D. 2015. "The circular economy, design thinking and education for sustainability." Local Economy, 30:3: 305-315.

Ballie, J. 2014. e-Co-Textile Design: How can textile design and making be combined with social media to promote sustainable fast fashion futures? PhD diss. London: University of the Arts London.

Ballie, J. Smith, P. McHattie, L. 2016. Re-Mantle and Make: the role of maker spaces in empowering a new wave of circular thinking for textile designers. Circular by Design Conference, London.

Bakker, C, A., R. Wever, Teoch, C., Clercq, S. 2010. "Designing cradle-to-cradle products: a reality check". International Journal of Sustainable Engineering, 3:1: 2-8.

Black, S. and Alexander, H. 2012. The Sustainable Fashion Handbook, London: Thames and Hudson.

Brandt, E., Binder, T. and Sanders, E.B.N. 2013. "Ways to Engage, Telling, Making and Enacting." International Handbook of Participatory Design, Oxford: Routledge, 145-181. Braungart, M., McDonough, W., Bollinger, A. 2007. "Cradle-to-cradle design: creating healthy emissions-a strategy for eco-effective product and system design." Journal of cleaner production, 15:13: 1337-1348.

Chapman, J. 2005. Emotionally durable design: objects, experiences and empathy. London: Earthscan.

Chick, A. and Micklethwaite, P. 2011. Design for Sustainable Change: How design and designers can drive the sustainability agenda. Worthing: AVA Academic.

Concoran, P.L., Moore, C.J. and Jazvac, K. 2014. "An anthropogenic marker horizon in the future rock record." GSA Today, 24.6: 4-8.

Cho, S. and Lee, J.H. 2015. "Development of Zero Waste Fashion Design Process Guideline from an Educational Perspective." Journal of the Korean Society of Costume, 65:4: 91-108.

Decastro, O. 2014. "Upcycling." Keynote at Scottish Textile Symposium. Glasgow, Scotland, November.

Dorst, K. 2008. “Design Research: a revolution-waiting-to-happen.” Design Studies, 29:3: 411.

Earley, R. and Goldsworthy, K. 2014. “TED’s Ten.” Keynote at Circular by Design Chiasma, Design in Action. Edinburgh, Scotland, March.

Earley, R. 2007. "The new designers: working towards our eco fashion future". In Dressing Rooms: Current Perspectives on Fashion and Textiles Conference, Oslo, Norway. 14-16.

Erikson, A. 2009. "Engaging design materials, formats and framings in specific, situated co designing - A Micro-material perspective." Proceedings of 2009 Nordes conference, Engaging Artifacts, Oslo, Norway. 1-10.

Fletcher, K., Grose, L. and Hawken, P. 2012. Fashion \& sustainability: Design for change. Laurence King. London.

Fletcher, K. 2011. Sustainable fashion and textiles: design journeys. London: Routledge. 2011. Goldsworthy, K. 2012. Laser-finishing: a new process for designing recyclability in synthetic textiles. PhD diss. London: University of the Arts London.

Goldsworthy, K. 2014. "Design for Cyclability: pro-active approaches for maximising material recovery." Making Futures, 3.

Gwilt, A. and Rissanen, T. 2011. "Shaping Sustainable Fashion: changing the way we make and use clothes". London: Routledge.

HYBRID MATTERS "HYBRID MATTERs - about", HYBRID MATTERs.

http://hybridmatters.net/pages/about Accessed July 29 2015. Kent, A. "Aimee Kent".

http://aimeekent.com accessed July $27^{\text {th }} 2016$.

Kane, F. (2017), "Materials design for sustainability: Connecting with local resource flows through the development of flax-based composites", 8: 1: 101-18.

Lucero, A., Vaajakallio, K. Dalsgaard, P. 2012. "The dialogue-labs method: process, space and materials as structuring elements to spark dialogue in co-design events" CoDesign, 8:1: 1-23. Manzini, E. 2005. Network, Localismo cosmopolita. Prospettive per uno sviluppo locale sostenibile ed ipotesi sul ruolo del design, Milano: Agenzia SDI. D.E.S.I.S. and London, U.A.L. 
McHattie, L-S., Champion, C. and Broadley, C. 2018. "Craft, textiles, and cultural assets in the Northern Isles: innovation from tradition in the Shetland Islands", Island Studies Journal (Ahead of Print).

Vezzoli, C.A. and Manzini, E. 2011. "Design for environmental sustainability". Springer Science \& Business Media.

McKInsey. 2015. "Growth within: A circular economy vision for a competitive Europe". https://www.ellenmacarthurfoundation.org/assets/downloads/publications/EllenMacArthurFoun dation_Growth-Within_July15.pdf

Payne, A. 2011. "The life-cycle of the fashion garment and the role of Australian mass market designers". The International Journal of Environmental, Cultural, Economic and Social Sustainability. 7(3), pp.237-246.

RSA and The Great Recovery. http://www.greatrecovery.org.uk Accessed May 122014. Sanders, E.B.N. and Stappers, P.J. 2008. "Co-creation and the new landscapes of design." CoDesign, 4:1 (2008): 5-18.

SCOTTISH ENTERPRISE "Scottish Textiles Skills Survey." 2013. http://www.stla.uk.com/wp content/uploads/2013/09/Scottish-Textiles-Skills-Survey-Report.pdf Accessed July 28th 2016. Shayler, M. and Maslin, R. "Service Design for a Circular Economy." The RSA Great Recovery. January $19^{\text {th }}, 2015$. http://www.greatrecovery.org.uk/service-design-for-a-circular-economy/

Simonella, A. (2016). Allenomis. http://www.allenomis.com accessed 27 th July 2016.

Steen, M. 2011. "Tensions in human-centred design." CoDesign, 7:1 (2011): 45-60.

Taylor, N. The Top Project. http://thetopproject.com accessed $27^{\text {th }}$ July 2016.

Taylor, J. and K. Townsend, K. 2014. "Reprogramming the hand: Bridging the craft skills gap in 3d/digital fashion knitwear design." Craft Research, 5:2: 155-174.

Tham, M. and Jones, T. 2008. "Metadesign tools. Designing the seeds for a shared process of change". Changing the Change Conference. An international conference on the role and potential of design research in the transition towards sustainability. Torino, Italy. July 10-12. Thomas, S. "Hacking the Circular Economy." The RSA Great Recovery Blog, April $2^{\text {nd }}, 2015$. Accessed May 12. https://www.thersa.org/discover/publications-and-articles/rsa blogs/2015/04/hacking-the-circular-economy/

Thakara, J. 2014. "A Whole New Cloth: Politics and the Fashion system." Routledge Handbook of Sustainability and Fashion. London: Routledge, 43-46.

Van Balgooi, F. 2015. "Master class one: Design for Disassembly". Zero Waste Scotland Public Lecture. University of Dundee. $2^{\text {nd }}$ December.

Yair, K. 2011. Craft and Rural Development, London: Crafts Council. 